\title{
Unmet support needs in teenage and young adult childhood brain tumour survivors and their caregivers: "it's all the aftermath, and then you're forgotten about"
}

\author{
Emma Nicklin ${ }^{1} \cdot$ Lucy Pointon $^{1} \cdot$ Adam Glaser $^{1} \cdot$ Naseem Sarwar $^{2} \cdot$ Michelle Kwok-Williams $^{2} \cdot$ Miguel Debono $^{3}$. \\ Galina Velikova $^{1}$. Florien W. Boele ${ }^{1,4}$ (D)
}

Received: 19 November 2020 / Accepted: 1 April 2021 / Published online: 16 April 2021

(C) The Author(s) 2021

\begin{abstract}
Purpose Teenage and young adult (TYA) survivors of childhood brain tumours and their family caregivers can experience many late effects of treatment that can hamper the transition to living independent lives. Yet, their long-term supportive care needs are largely unknown. We investigated the supportive care needs of TYA survivors and their caregivers and explored the role and perceived use of support.

Methods Face-to-face semi-structured interviews were conducted with survivors aged 16-30 $(n=11)$ who were $\geq 5$ years after diagnosis and caregivers $(n=11)$. Interviews were recorded and transcriptions thematically analysed.

Results Four themes emerged: (1) preferences for support and support services (unmet needs). Concerns regarding mental health, employment and financial uncertainty, the desire to live independently, and lack of support were emphasised. (2) Decline in support. Caregivers noted a drop-off in support available when transitioning to adult services. (3) Reasons for not obtaining adequate support. Several barriers to accessing support were raised, including distance and aging out of services. (4) The role of long-term hospital-based follow-up care. Participants highlighted the importance of, and reassurance from, long-term follow-up care but noted a more all-inclusive approach is required.

Conclusions Even many years after diagnosis, TYA childhood brain tumour survivors and their caregivers continue to have unmet supportive care needs. Both TYA survivors and their caregivers can benefit from support to meet their unique needs and improve long-term quality of life. Understanding unmet needs and recognising what services are required due to the late effects of treatment is critical to improving long-term quality of survival.
\end{abstract}

Keywords Brain tumour $\cdot$ Teenage young adult $\cdot$ Survivorship $\cdot$ Family caregiver $\cdot$ Supportive care $\cdot$ Unmet needs $\cdot$ Late effects

\section{Introduction}

In children, there are over 100 histological entities for childhood brain tumours, the most common of which are gliomas accounting for around $50 \%[1,2]$. Incident rates for children aged $0-19$ for central nervous system tumours are 6.06 per

Florien W. Boele

F.Boele@leeds.ac.uk

1 Leeds Institute of Medical Research at St James's, University of Leeds, Leeds, UK

2 Leeds Teaching Hospitals NHS Trust, Leeds, UK

3 Sheffield Teaching Hospitals NHS Foundation Trust, Sheffield, UK

4 Leeds Institute of Health Sciences, University of Leeds, Leeds, UK
100,000 [2]. Many children become teenage and young adult cancer survivors (TYAs - broadly defined in the literature as patients aged 13-39 [3]), facing specific challenges different from those of younger children or older adults.

Treatment chosen depends on tumour type, location, and age, often involving multimodal approaches including surgery, irradiation, chemotherapy, and medication [4]. While treatments for childhood cancer have improved in minimising adverse effects and maximising long-term survival $[5,6]$, survivors commonly experience substantial changes in their developmental trajectories [7]. With longer survival, late effects (e.g. physical, social, emotional, behavioural, and neurocognitive issues) are particularly important for quality of life (QoL). Indeed, childhood brain tumour survivors are at risk of worse QoL when compared to the general population and other TYAs [8-10]. 
A childhood brain tumour also impacts greatly on those closest to the patient. The responsibility for caring and supporting childhood brain tumour survivors is often met by their parents. Adapting to a new role as informal caregiver can be rewarding but also causes significant distress and burden [11]. With care demands combining those of cancer and a brain injury, high caregiver burden is associated with depressive symptoms and lower self-esteem [11-13]. Understanding caregivers' and survivors' ongoing support needs is vital.

TYAs remain at risk of late effects $[14,15]$. TYAs frequently experience cognitive deficits, such as memory and attention difficulties which can have further negatively impact on cognitive development, independent living, academic achievement, and social functioning [16-18]. Many TYAs have difficulties in navigating social and romantic relationships $[19,20]$. They are often faced with tension between their emerging abilities as they move through adolescence and into young adulthood and their limitations imposed by their illness [21].

These challenges can persist for the survivors' lifetime and may require long-term tailored support and care. Long-term follow-up clinics can offer coordinated, multidisciplinary care addressing survivors' and caregivers' issues [22-24]. To improve services, having a clear overview of unmet supportive care needs of TYA survivors of childhood brain tumours and their caregivers is crucial - yet, we found little research addressing this in our recent systematic review [25]. We aimed to describe supportive care needs of TYA childhood brain tumour survivors and their caregivers and explore the role and perceived use of support services. More knowledge in this area is critical to improving quality of survival.

\section{Methods}

\section{Study design}

We present the qualitative work stream of a larger mixed methods project. The current project consists of in-depth, semi-structured face-to-face interviews. The consolidated criteria for reporting qualitative research (COREQ) were used in this report [26]. All quotes are pseudonymized. The study was approved by Yorkshire \& the Humber - Bradford Leeds Research Ethics Committee (18/YH/0312).

\section{Participants}

TYA childhood brain tumour survivors (hereafter called "survivors") and their caregivers were recruited from long-term followup clinics at Leeds and Sheffield National Health Service (NHS) Trusts between November 2018 and January 2020, using maximum variation sampling to ensure a varied range of sex, age, and brain tumour type. The lead author (EN) liaised closely with clinicians (including AG, NS, MKW, MD) to ensure participants were representative of the population.

Survivors were invited to participate if aged between 13 and 30 ; diagnosed before the age of $14 ; \geq 5$ years posttreatment; and able to understand English. Caregivers were eligible to participate in the study if they were English-speaking, primary caregivers of a survivor. Survivors and caregivers did not have to be pairs from the same family. Written consent was obtained from all participants.

\section{Data collection}

The interviews followed an interview guide (Table 1) consisting of open-ended questions, developed through a systematic review [25]. Participants were interviewed individually; however if preferred (e.g. if the survivor required support), survivors and caregivers could be interviewed together. Data collection ceased when saturation was achieved [27]. All interviews were audio recorded and transcribed verbatim.

\section{Analysis}

Thematic analysis [28] was conducted by one coder (EN, PhD candidate), supported closely by more senior researchers (FWB and GV, supervisors). We used Braun and Clarke's [29] 6-step framework, (step 1, transcription, immersion, and familiarisation; step 2, generating initial codes; step 3, searching for themes; step 4 , reviewing and revising themes; step 5, defining themes; step 6 , writing-up) to develop a clear and consistent approach to exploring survivors and their caregivers' experiences. Following verbatim transcription [30], the transcripts were re-read to promote "immersion in the data", allowing familiarisation to occur. The data could then be read actively, analytically, and critically [31]. Coding was conducted using NVivo software, with a subset of four interviews coded independently by a second coder (FWB), both coders then met to discuss and refine codes. Key outcomes were refined into themes reflecting participants' experiences. Survivor and caregiver interviews were analysed simultaneously. Finally another researcher (LP, research assistant) examined all transcripts post-analysis to ensure analytical robustness and validity. Throughout analysis, any differences or disagreements between coders or checkers (EN, FWB, LP, GV) were resolved through discussion and/or re-examination of transcripts.

\section{Results}

In total 21 survivors and 18 caregivers were approached, 22 (11 survivors; 11 caregivers) consented and took part. Interviews were conducted in participants' home or a hospital room. In two cases, survivors and caregivers were interviewed together. Interviews averaged 53 minutes (range: 15-140). Data saturation was reached by the 22 nd interview. 
Table 1 Interview guide

\begin{tabular}{ll}
\hline Interview topics & Key questions \\
\hline $\begin{array}{l}\text { Survivor - after } \\
\text { diagnosis/treatment }\end{array}$ & - How has life been since [survivor's] brain tumour diagnosis? \\
-Changes/difficulties faced? & -Have there been any impacts to employment or education? \\
Caregiver challenges & - What are the main changes/challenges since the diagnosis/treatment? \\
& - Have these challenges changed since [survivor] entered adolescence? \\
If so how? & Survivor questions \\
Support services & - What services have been involved in your after care? (e.g. charities) \\
and service use & - When did you receive this (during/after treatment)? \\
& - Could these services be improved? \\
& Caregiver questions \\
& - What support did you receive and how were you made aware? \\
- Do you think these services could be improved? & - What is the benefit of attending clinics? \\
- Is what is discussed in clinic is understandable for you? (Survivor specific) \\
- Do you feel that these clinics are age appropriate for survivors? \\
(Caregiver specific) \\
- Is there anything you would have liked or would now like more support with? \\
Distinguish between patient support and caregiver support. \\
- What information should be given to survivors and caregivers? \\
- Are there any particular resources that should be provided for survivors as \\
they become older? \\
- How can support and the way you are informed about support be improved? \\
\hline
\end{tabular}

Tables 2 and 3 show participant characteristics. The most common tumour type was astrocytoma (survivor sample) and medulloblastoma (caregiver sample). Most survivors lived with their parents, not independently. Few survivors were employed $(n=2)$ and the majority were single $(n=10)$.

We found four over-arching themes: (1) preferences for support and support services (unmet needs); (2) decline in support; (3) reasons for not obtaining adequate support; and (4) the role of long-term follow-up care. Key learning points are summarised in Table 4.

\section{Theme 1: preferences for support and services}

\section{Achieving key life events}

For caregivers and survivors, achieving "normal" life goals such as paid employment is very important, and the prospect of not achieving these caused concern. Most survivors experienced difficulty or were unable to find employment. Survivors expressed that they need more information on gaining employment. Unmet support needs included help with finding employers who are "disability friendly", help preparing CVs/application forms, and interview support. Survivors' financial issues were a major concern to caregivers, in particular if and how the survivor could support themselves.

The main challenges, well is finance, financial...It's stressful cos I want [survivor name] to have some income, you know, cos I can't support her, do you know what I mean....and that's what worries me. [C8, F, 58 $\left.{ }^{1}\right]$

Difficulties with employment and finances are linked with independent living. Almost all survivors were still living with their family. They hoped to someday live independently but acknowledged this may take time.

I don't even know how to cook now and I'm 27 and that's because it's very slow...I'm still picking up the pieces now...And how long I'm going to be picking them up for I don't know? [S6, F, 27]

While independent living was a key goal for survivors, caregivers highlighted that for some (e.g. those with many physical impairments or learning difficulties prompting a need for continued intensive support) this

\footnotetext{
${ }^{1} \mathrm{C}=$ caregiver number. $\mathrm{S}=$ survivor number. $\mathrm{F}=$ female. $\mathrm{M}=$ male. Number $=$ current age
} 
Table 2 Survivor characteristics

\begin{tabular}{|c|c|c|c|c|c|c|c|c|}
\hline & Sex & Current Age & Employment status & $\begin{array}{l}\text { Living } \\
\text { status }\end{array}$ & $\begin{array}{l}\text { Relationship } \\
\text { status }\end{array}$ & $\begin{array}{l}\text { Age at } \\
\text { diagnosis }\end{array}$ & Diagnosis & Education \\
\hline S1 & $\mathrm{F}$ & 16 & Student & Family & Single & 1 & Pilomyxoid astrocytoma & Mainstream school \\
\hline S2 & M & 30 & $\begin{array}{l}\text { Unemployed — but } \\
\text { looking for work }\end{array}$ & Family & Single & 6 & Pilocytic astrocytoma & Mainstream school \\
\hline S3 & M & 22 & $\begin{array}{l}\text { Unable to work due to } \\
\text { illness or disability }\end{array}$ & Family & Single & 10 & $\begin{array}{l}\text { Primitive neuroectodermal } \\
\text { tumour }\end{array}$ & Mainstream school \\
\hline S4 & $\mathrm{F}$ & 28 & Working $\mathrm{F} / \mathrm{T}^{\mathrm{a}}$ & Partner & In a relationship & 10 & Pilocytic astrocytoma & Mainstream school \\
\hline S5 & M & 18 & Student & Family & Single & 9 & Oligodendroglioma & Mainstream school \\
\hline S6 & $\mathrm{F}$ & 27 & Working $\mathrm{F} / \mathrm{T}^{\mathrm{a}}$ & Family & Single & 5 & Pilocytic astrocytoma & Mainstream school \\
\hline S7 & M & 24 & $\begin{array}{l}\text { Unemployed -but } \\
\text { looking for work }\end{array}$ & Family & Single & 10 & Medulloblastoma & Mainstream school \\
\hline S8 & F & 25 & $\begin{array}{l}\text { Unemployed -but } \\
\text { looking for work }\end{array}$ & Family & Single & 7 & Medulloblastoma & Mainstream school \\
\hline S9 & F & 26 & $\begin{array}{l}\text { Unable to work due } \\
\text { to illness or disability }\end{array}$ & Family & In a relationship & 2 & Medulloblastoma & Mainstream school \\
\hline S10 & M & 30 & $\begin{array}{l}\text { Unable to work due to } \\
\text { illness or disability }\end{array}$ & Family & Single & 5 & $\begin{array}{l}\text { Primitive neuroectodermal } \\
\text { tumour }\end{array}$ & Mainstream school \\
\hline S11 & $\mathrm{F}$ & 17 & Student & Family & Single & 4 & Anaplastic ependymoma & Mainstream school \\
\hline
\end{tabular}

${ }^{\mathrm{a}} \mathrm{F} / \mathrm{T}=$ full-time employment. $\mathrm{P} / \mathrm{T}=$ part-time employment

goal is not achievable. Caregivers' major concern was what would happen when they were no longer able to care for them.

That's one of my biggest fears, not saying [name of wife] couldn't look after him but...erm if owt happened to me then how would they cope? [C2, M, 58]

Caregivers expressed a need for more information on support to help survivors transition into independent or assisted living. This would help them plan ahead and decrease their anxiety about the future.

\section{Developing a social network}

Survivors and caregivers discussed that forming social relationships has been difficult. Some survivors indicated they would like support with making and maintaining friendships, finding social interactions difficult; "Like sometimes in my head I'm thinking 'don't trip up, don't trip up"' [S1, F, 16$]$.

Table 3 Caregiver characteristics

\begin{tabular}{|c|c|c|c|c|c|c|c|c|c|c|}
\hline & Sex & Age & $\begin{array}{l}\text { Employment } \\
\text { status }\end{array}$ & $\begin{array}{l}\text { Relationship } \\
\text { status }\end{array}$ & $\begin{array}{l}\text { Survivor } \\
\text { sex }\end{array}$ & $\begin{array}{l}\text { Age at } \\
\text { diagnosis }\end{array}$ & $\begin{array}{l}\text { Relationship } \\
\text { to survivor }\end{array}$ & $\begin{array}{l}\text { Survivor } \\
\text { current } \\
\text { age }\end{array}$ & Survivor diagnosis & Survivor education \\
\hline $\mathrm{C} 1$ & $\mathrm{~F}$ & 47 & Working $\mathrm{F} / \mathrm{T}$ & Married & $\mathrm{F}$ & 1 & Mother & 16 & Pilomyxoid astrocytoma & Mainstream school \\
\hline $\mathrm{C} 2$ & $\mathrm{M}$ & 58 & Working $\mathrm{F} / \mathrm{T}$ & Married & $\mathrm{M}$ & 6 & Father & 30 & Pilocytic astrocytoma & Mainstream school \\
\hline $\mathrm{C} 3$ & $\mathrm{~F}$ & 55 & Working $\mathrm{P} / \mathrm{T}$ & Married & M & 6 & Mother & 30 & Pilocytic astrocytoma & Mainstream school \\
\hline $\mathrm{C} 4$ & $\mathrm{~F}$ & 56 & Working $\mathrm{F} / \mathrm{T}$ & Married & M & 10 & Mother & 22 & $\begin{array}{l}\text { Primitive } \\
\text { neuroectodermal } \\
\text { tumour }\end{array}$ & Mainstream school \\
\hline $\mathrm{C} 5$ & $\mathrm{~F}$ & 50 & Working $\mathrm{F} / \mathrm{T}$ & Married & $\mathrm{M}$ & 9 & Mother & 18 & Oligodendroglioma & Mainstream school \\
\hline C6 & $\mathrm{F}$ & 53 & Working $\mathrm{P} / \mathrm{T}$ & Married & M & 10 & Mother & 24 & Medulloblastoma & Mainstream school \\
\hline $\mathrm{C} 7$ & $\mathrm{~F}$ & 61 & Working F/T & Divorced & $\mathrm{F}$ & 7 & Mother & 25 & Medulloblastoma & Mainstream school \\
\hline $\mathrm{C} 8$ & $\mathrm{~F}$ & 54 & $\begin{array}{l}\text { Caring for } \\
\text { family/home }\end{array}$ & Married & $\mathrm{F}$ & 2 & Mother & 26 & Medulloblastoma & Mainstream school \\
\hline C9 & $\mathrm{F}$ & 50 & Working $\mathrm{P} / \mathrm{T}$ & Married & M & 5 & Mother & 30 & $\begin{array}{l}\text { Primitive } \\
\text { Neuroectodermal } \\
\text { tumour }\end{array}$ & Mainstream school \\
\hline C10 & $\mathrm{F}$ & 49 & Working $\mathrm{P} / \mathrm{T}$ & Separated & $\mathrm{F}$ & 4 & Mother & 17 & Anaplastic ependymoma & Mainstream school \\
\hline C11 & $\mathrm{F}$ & 40 & $\begin{array}{l}\text { Caring for } \\
\text { family/home }\end{array}$ & Single & $\mathrm{F}$ & 4 & Mother & 14 & Medulloblastoma & $\begin{array}{l}\text { Special educational } \\
\text { needs school }\end{array}$ \\
\hline
\end{tabular}


Table 4 Key learning points from each theme

\begin{tabular}{|c|c|c|}
\hline Theme & Key learning point & $\begin{array}{l}\text { Survivors and/or } \\
\text { caregivers }\end{array}$ \\
\hline \multirow[t]{2}{*}{$\begin{array}{l}\text { 1: Preferences for support } \\
\text { and support services } \\
\text { (unmet needs) }\end{array}$} & $\begin{array}{l}\text { A preference for support that focuses on "achieving life events" } \\
\text { such as living independently and making and maintaining } \\
\text { relationships }\end{array}$ & Survivors \\
\hline & $\begin{array}{l}\text { A preference for support that assists with financial and practical } \\
\text { elements of independent living. This may assist in helping both survivors } \\
\text { and caregivers achieve those future goals }\end{array}$ & Caregivers \\
\hline 2: Decline in support & $\begin{array}{l}\text { A drop in availability of services once the survivor completed treatment } \\
\text { is a concern, especially as survivors become more aware of their } \\
\text { health and the limitations they may face. Support services should } \\
\text { endeavour to continue supporting survivors and their caregivers in } \\
\text { long-term survivorship }\end{array}$ & Survivors and Caregivers \\
\hline \multirow[t]{3}{*}{$\begin{array}{l}\text { 3: Reasons for not obtaining } \\
\text { adequate support }\end{array}$} & $\begin{array}{l}\text { Providing lay-friendly information is crucial for survivors so that they } \\
\text { can understand the implications of their diagnosis/treatment }\end{array}$ & Survivors \\
\hline & $\begin{array}{l}\text { Resources/training for clinicians to facilitate the transition from } \\
\text { addressing parents to addressing patients may be beneficial to } \\
\text { follow-up care in general and support in particular }\end{array}$ & Survivors \\
\hline & $\begin{array}{l}\text { The dependence on informal support by caregivers highlights the } \\
\text { variation in support services available due to location, funding, and } \\
\text { unclear information. Consistency in support services is key to } \\
\text { ensuring caregivers receive adequate professional support }\end{array}$ & Caregivers \\
\hline $\begin{array}{l}\text { 4: The role of long-term } \\
\text { follow-up care }\end{array}$ & $\begin{array}{l}\text { The need for continuity of support. The continuation of long-term } \\
\text { follow-up was "easier" when the clinical teams remained the same. } \\
\text { Childhood cancer survivors benefit from joint working practices } \\
\text { especially during the transition from child to adult services }\end{array}$ & Survivors and caregivers \\
\hline
\end{tabular}

Several survivors said that they would like to meet other survivors, but connecting with peers (i.e. similar age group) is the most important factor. Caregivers were equally worried about their child's lack of social life and were supportive of meeting individuals with shared experiences through organised social support groups.

They've all got something in common, they don't have to be talking about that all the time but they can all find this common ground. [C8, F, 54]

\section{Navigating the future}

Caregivers recalled that during the survivor's diagnosis and treatment, they were not always aware of potential late effects, or they may not have fully realised at the time.

I've kind of had to go back over it myself to make it make sense again now, cos I think you're given a lot of information in the early days but it just doesn't go in... [C10, F, 49]

Caregivers highlighted that better timing of information on late effects and the need for ongoing contact and support alongside the survivors changing needs were vital. As this timing is difficult to get right, they suggested that such information could be reintroduced regularly.

\section{Personalised, individualised mental health support}

Mental health services were considered crucial. Survivors explained this was still needed long-term due to a growing understanding of their diagnosis and the experience of late effects.

I had counselling when I was 7 but I still want help now I'm 25... I don't want that help to have just stopped... cos there's still things that are happening and changing... the side effects never leave you if you know what I mean? [S8, F, 25]

The majority of survivors indicated that although they had received counselling during treatment, this subsided in later life. Some survivors stated that they would appreciate having a mentor or somebody who could provide 1-1 help. This was echoed by caregivers, some of whom felt that this was one of the greatest unmet needs.

I would like there to be like a mentor or a person who you could ring...somebody that you could contact to talk to about that certain thing that you want information on. $[\mathrm{C} 8, \mathrm{~F}, 54]$ 
Survivors wanted this mentor to have knowledge of brain tumours to help guide them through life experiences complicated by late effects. Caregivers wanted a reliable point of contact.

\section{Theme 2: decline in support}

\section{Life after education}

Survivors and caregivers described support from education generally as positive. Support provided included care assistants (e.g. for mobility/personal care), additional time, or adapted educational aids.

I had modified papers, they were on green paper and a bigger font...It's the spacing really that's more helpful. [S11, F, 17]

High schools and colleges were often given formal advice and guidance to help them support survivors (e.g. through vision support officers). Survivors and caregivers described that difficulties started after finishing education, when support stopped and survivors felt at a loss of what to do next.

When I finished college it's like - what am I supposed to do after that? [S10, M, 30]

\section{Diminishing support getting further away from treatment}

All caregivers were particularly positive about support received from clinical teams, charities, and support services, while their child was in treatment or acute care. However, many felt that support fell away as the child moved further away from treatment.

At the time it was just hospitals all the time. And I think [survivor] felt quite safe and I think it sounds quite a strange thing to say but we both felt quite safe but when you come out of hospital...you feel really lost... [C4, F, $56]$

Caregivers and survivors described being unable to access support services once they reached adulthood.

\section{Theme 3: barriers to not obtaining adequate support}

\section{Practical barriers to accessing support}

Caregivers said they were not aware of long-term support available or how to access support. "We didn't really know what other support groups were in place... so we didn't really know where you would go and look" [C1, F, 47]. Other barriers include support or information not being in an accessible format for survivors (e.g. due to vision/cognitive issues), long waiting lists, and lack of funding.

The waiting lists for everything are just immense...one thing we've been trying to get help with is to see a psychologist...we've still not seen a psychologist and this is 2 years on $[\mathrm{C} 9, \mathrm{~F}, 50]$

Equally, location of support services was challenging, complicated by difficulties with transportation. This was especially salient in participants living in rural areas:

A lot of the problem we have is because were in this dead zone - were surrounded by big Cities, it means we have to travel to the City to do anything $[\mathrm{C} 9, \mathrm{~F}, 50]$

Having negative experiences of support services could cause reluctance to access support. Some describe bad experiences which include being let down or forgotten about.

They [the charity] sent a lady who was going to take him out and meet up with some other young man quite near us but that never transpired. [C6, F, 53]

Another issue identified is the lack of brain tumour specific support. Some survivors received support from cancer charities but felt that this was not suitable for their experiences, in particular their late effects.

I seeked out help but I found they always put me in learning disability groups but not brain tumour type... [S7, M, 24]

\section{"Getting on with it": emotional barriers to support}

Survivors and caregivers explained a main reason for not having accessed support was that they were just "getting on" with life. Most caregivers had never received any formal support for themselves (e.g. counselling), instead relying heavily on friends or family for emotional support. Caregivers appeared to not prioritise their own needs, often saying they do not need it or choosing to cope on their own:

It's hard but it's called life and you have to get on with it! [C8, F, 54]

Survivors also expressed a positive outlook on life, and if they could, they chose not to seek formal support and manage on their own: 
Like with the emotional stuff I just get on with it. There's nothing like...like my chemo does, did affect me but I've just got over it. [S5, M, 18]

Both survivors and their caregivers expressed that "getting on with it" is synonymous with "seeming to be in control of the situation". Survivors typically saw this as a positive outcome, but some caregivers indicated they had few choices but to "get on with it" and cope.

\section{Theme 4: the role of long-term follow-up care}

\section{Importance of follow-up care}

Survivors and caregivers said the main benefit from attending long-term follow-up appointments was reassurance. Survivors described these appointments as a reassuring yearly check-up. Equally, caregivers found these appointments a valuable opportunity to ask questions and check late effect symptomology.

Just to get checked up, it's an MOT [annual test of vehicle safety in the UK]. [S1, F, 16]

Many caregivers also said this service signposts them to other supports (e.g. charities) which could help the survivor live better.

\section{Transition from children's to adult services}

Some survivors and caregivers described the transition from children's to adult services as uncertain and confusing. Some survivors and caregivers said more support and information is needed to aid this transition.

The transition was easier where there was continuity in clinical staff and/or hospital.

It was quite an easy transition, it was same people, same place! It is that familiarity, it's that person...I don't have to explain everything, I don't have to explain everything with [survivor], cos they know - they've been there all the way through! [C9, F, 50]

\section{How follow-up care could be improved}

A small number of survivors indicated that clinicians did not engage with them enough or fully explain their medication or treatments.
They need to engage more with the child than they do with the parents... I didn't understand why I was on medication, apart from my Mum telling me...but a consultant physically did not tell me why I was on it, so when I would go pick my prescriptions up at the age of 18 and the consultants saying why are you on this...I would say 'I don't know'. [S6, F, 27]

With many survivors struggling with cognitive deficits, the use of lay language is essential. Survivors wanted clinicians to check their understanding:

Sometimes some of the doctors say things....again it's a bit difficult to understand them or process what they're saying, I don't quite understand the terminology. [S8, F, 25]

Caregivers hoped support could be improved by extending it beyond just medical care to holistic or social well-being care, e.g. job application support.

Survivors and their caregivers report a number of similar goals with subtle differences in their unmet support needs; in particular they both express a desire for more emphasis and information on future outcomes. For survivors this includes the ability to live independently and assistance with attaining this goal. Caregivers expressed a need for financially centred information.

\section{Discussion}

This qualitative study provides insight into the unmet supportive care needs of TYA childhood brain tumour survivors and their caregivers. Our findings suggest that survivors are greatly concerned with their ability to live independently, find employment, and build and maintain social connections. Previous survey-based TYA cancer survivor research (not brain tumour-specific) similarly highlighted the need for support with making and maintaining friendships, but did not yet cover "achieving life events" [32]. Parents are very aware of the need for socialisation outside of the family, a finding supported by previous literature [33]. We found that caregivers are concerned with what will happen if they can no longer support the survivor both practically (financially and physically) as well as emotionally. Previous TYA brain tumour research similarly reports caregiver concerns over inadequate financial support and a decline in support available after treatment $[34,35]$.

Adolescence and early adulthood is a unique and complex developmental phase consisting of sensitive physical and emotional challenges [36], complicated by survivors' experiences of varying degrees of late effects. It is therefore 
unsurprising that survivors in our study most often wanted mental health and one-to-one support. Both survivors and caregivers explained that they felt a drop in service availability after treatment. This was of particular concern to survivors who, as they grew older, understood more about their health and late effects. Yet, mental health support is typically not part of usual follow-up care, highlighting an area of significant unmet needs. While this is in line with previous research suggesting that more comprehensive follow-up services for childhood cancer survivors are required [22-24, 37], our findings confirm these needs are still unmet in TYAs.

In our study, barriers to accessing formal support included funding and unclear or conflicting information which could create confusion about the applicability of support options. Location and transport were highlighted as barriers by caregivers living in rural areas in particular. Participants stressed the importance of providing lay-friendly information and providing it to survivors directly instead of via caregivers. This is supported by studies in childhood cancer survivors [33]. In addition, resources or training for clinicians to facilitate the transition from addressing parents to survivors may be beneficial to follow-up care in general and support in particular.

The need for continuity of support was also highlighted; participants explained long-term follow-up was "easier" when clinical staff or services remained the same. Survivors expressed a benefit from seeing "familiar faces". Indeed, childhood cancer survivors can benefit from multimodal and joint working practices in transitioning from child to adult services [38]; this is particularly important for survivors who are not living independently [39].

While this study holds its strengths in talking to both survivors and caregivers using in-depth qualitative interviews, it does have its limitations. We recruited participants attending long-term follow-up clinics, thus likely underestimating unmet needs of survivors and caregivers who do not access these clinics. Moreover, we defined TYA as $13-30$ years old, while throughout the oncology literature, there is great disparity over the definition of TYA age ranges [40]. While we aimed for maximum variation sampling, the final sample may not reflect non-English-speaking families, survivors aged under 16 and those diagnosed between 10 and 14 . When younger survivors were approached for recruitment their parents often declined due to survivors' cognitive deficits. A small number of non-English-speaking survivors and caregivers were not eligible for participation due to lack of translation resources. These may be subgroups with even higher unmet needs.

This study highlights survivors' and caregivers' unmet support needs, barriers to obtaining support, and improvements that could be made to long-term follow-up care. The practical suggestions made can provide stepping stones to improving long-term follow-up care, enhancing quality of life for TYA childhood brain tumour survivors and their caregivers.
Author contribution Funding was acquired by Florien W. Boele and Galina Velikova. Emma Nicklin, Galina Velikova, and Florien W. Boele designed the study. Adam Glaser, Naseem Sarwar, Michelle Kwok-Williams, and Miguel Debono reviewed patients for inclusion in the study. Emma Nicklin and Florien W. Boele designed the analysis plan. Emma Nicklin performed the data analysis, supported by Florien W. Boele, Galina Velikova, and Lucy Pointon. All authors advised on data analysis and interpretation. Emma Nicklin, Lucy Pointon, and Florien W. Boele wrote the first draft of the manuscript, which was reviewed and approved by all authors

Funding Funding for this work was provided by Ellie's Fund and Yorkshire Cancer Research — Grant Ref Number: L389FB (PI: FWB).

Availability of data and materials Data are held securely by the research team and may be available upon reasonable request and with relevant approvals in place.

Code availability Not applicable.

\section{Declarations}

Ethics approval All procedures performed in studies involving human participants were in accordance with the ethical standards of the institutional and/or national research committee and with the 1964 Helsinki declaration and its later amendments or comparable ethical standards.

Consent to participate All participants provided written, informed consent.

Consent for publication All participants provided consent for publication

Conflicts of interest - Financial interests: Authors Emma Nicklin, Lucy Pointon, Adam Glaser, Naseem Sarwar, Michelle Kwok-Williams , Miguel Debono, and Florien W. Boele declare they have no financial interests. Author Galina Velikova has received personal fees from Roche, Eisai and Novartis.

- Non-financial interests: None.

Open Access This article is licensed under a Creative Commons Attribution 4.0 International License, which permits use, sharing, adaptation, distribution and reproduction in any medium or format, as long as you give appropriate credit to the original author(s) and the source, provide a link to the Creative Commons licence, and indicate if changes were made. The images or other third party material in this article are included in the article's Creative Commons licence, unless indicated otherwise in a credit line to the material. If material is not included in the article's Creative Commons licence and your intended use is not permitted by statutory regulation or exceeds the permitted use, you will need to obtain permission directly from the copyright holder. To view a copy of this licence, visit http://creativecommons.org/licenses/by/4.0/.

\section{References}

1. Louis D, Perry A, Reifenberger G, Deimling A, Figarella-Branger D, Cavenee W, Ohgaki H, Wiestler O, Kleihues P, Ellison D (2016) The 2016 World Health Organization classification of tumors of the central nervous system: a summary. Acta Neuropathol 131(6):803820. https://doi.org/10.1007/s00401-016-1545-1 
2. Ostrom QT, Cioffi G, Gittleman H, Patil N, Waite K, Kruchko C, Barnholtz-Sloan JS (2019) CBTRUS statistical report: primary brain and other central nervous system tumors diagnosed in the United States in 2012-2016. Neuro-oncology 21(5):v1-v100. https://doi.org/10.1093/neuonc/noz150

3. Aubin Sylvie BR, Paul R, Brent S, Bielack Stefan S, Andrea F, Manchester Ralph A, Kristin MM, Sue M, Melanie P, Sergio PA, Josep-Maria R, Peter S, Thomas David M, Claire T (2011) What should the age range be for AYA Oncology? J Adolesc Young Adult Oncol 1(1):3-10. https://doi.org/10.1089/jayao.2011.1505

4. National Institute for Health and Clinical Excellence (2006). Improving outcomes for people with brain and other CNS tumours. Available from: https://www.nice.org.uk/guidance/csg10/ resources/improving-outcomes-for-people-with-brain-and-othercentral-nervous-system-tumours-update-pdf-27841361437

5. Gibson TM, Mostoufi-Moab S, Stratton KL, Leisenring WM, Barnea D, Chow EJ, Donaldson SS, Howell RM, Hudson MM, Mahajan A, Nathan PC, Ness KK, Sklar CA, Tonorezos ES, Weldon CB, Wells EM, Yasui Y, Armstrong GT, Robison LL, Oeffinger KC (2018) Temporal patterns in the risk of chronic health conditions in survivors of childhood cancer diagnosed 1970-99: a report from the Childhood Cancer Survivor Study cohort. Lancet Oncol 19(12):1590-1601. https://doi.org/10.1016/S1470-2045(18) 30537-0

6. Packer RJ (2008) Childhood brain tumors: accomplishments and ongoing challenges. J Child Neurol 23(10):1122-1127. https://doi. org $/ 10.1177 / 0883073808320758$

7. Ris MD, Grosch M, Fletcher JM, Metah P, Kahalley LS (2017) Measurement of neurodevelopmental changes in children treated with radiation for brain tumors: what is a true 'baseline?'. The Clinical Neuropsychologist 31(2): 307-328. https://doi.org/10. 1080/13854046.2016.1216070

8. Aukema EJ, Schouten-van Meeteren AYN, Last BF, Maurice-Stam H, Grootenhuis MA (2013) Childhood brain tumor survivors at risk for impaired health-related quality of life. J Pediatr Hematol Oncol 35(8):603-609. https://doi.org/10.1097/MPH.0b013e31829b7ec6

9. Brinkman T, Li Z, Neglia J, Gajjar A, Klosky J, Allgood R, Stovall M, Krull K, Armstrong G, Ness K (2013) Restricted access to the environment and quality of life in adult survivors of childhood brain tumors. J Neuro-Oncol 111(2):195-203. https://doi.org/10.1007/ s11060-012-1001-6

10. Stam H, Grootenhuis MA, Caron HN, Last BF (2006) Quality of life and current coping in young adult survivors of childhood cancer: positive expectations about the further course of the disease were correlated with better quality of life. Psycho-Oncology 15(1):31-43. https://doi.org/10.1002/pon.920

11. Minaya Flores P, Berbis J, Chinot O, Auquier P (2014) Assessing the quality of life among caregivers of patients with gliomas. Neuro-Oncol Pract 1(4):191-197. https://doi.org/10.1093/nop/ npu027

12. Choi EK, Yoon SJ, Kim JH, Park HJ, Kim JY, Yu ES (2016) Depression and distress in caregivers of children with brain tumors undergoing treatment: psychosocial factors as moderators. PsychoOncology 25(5):544-550. https://doi.org/10.1002/pon.3962

13. Sherwood P, Ren D, Given CW, Donovan H, Weimer J, Belcher S, Given B (2016) The impact of caregivers' depression on their physical health. Psycho-Oncology 25 (SP. S3):24-24

14. Anderson DM, Rennie KM, Ziegler RS, Neglia JP, Robison LR, Gurney JG (2001) Medical and neurocognitive late effects among survivors of childhood central nervous system tumors. Cancer 92(10):2709-2719. https://doi.org/10.1002/1097-0142(20011115) 92:10<2709::AID-CNCR1625>3.0.CO;2-D

15. Turner CD, Rey-Casserly C, Liptak CC, Chordas C (2009) Late effects of therapy for pediatric brain tumor Survivors. J Child Neurol 24(11):1455-1463. https://doi.org/10.1177/ 0883073809341709
16. Brinkman TM, Reddick WE, Luxton J, Glass JO, Sabin ND, Srivastava DK, Robison LL, Hudson MM, Krull KR (2012) Cerebral white matter integrity and executive function in adult survivors of childhood medulloblastoma. Neuro-oncology 14(supp14): iv25. https://doi.org/10.1093/neuonc/nos214

17. Maddrey A, Bergeron J, Lombardo E, McDonald N, Mulne A, Barenberg P, Bowers D (2005) Neuropsychological performance and quality of life of 10 year survivors of childhood medulloblastoma. J Neuro-Oncol 72(3):245-253. https://doi.org/10.1007/ s11060-004-3009-Z

18. Wilford J, Buchbinder D, Fortier MA, Osann K, Shen V, Torno L, Sender LS, Parsons SK, Wenzel L (2017) "She Was a Little Social Butterfly": A qualitative analysis of Parent perception of social functioning in adolescent and young adult brain tumor survivors. J Pediatr Oncol Nurs 34(4):239-249. https://doi.org/10.1177/ 1043454216688660

19. Boydell KM, Stasiulis E, Greenberg M, Greenberg C, Spiegler B (2008) I'll show them: the social construction of (in)competence in survivors of childhood brain tumors. J Pediatr Oncol Nurs 25(3): 164-174. https://doi.org/10.1177/1043454208315547

20. Lehmann Vicky TMA, Keim Madelaine C, Mariët H, Gerhardt CA (2017) Am I a 6 or a 10? mate value among young adult survivors of childhood cancer and healthy peers. J Adolesc Young Adult Oncol 7(1):72-78

21. Freyer DR (2004) Care of the dying adolescent: special considerations. Pediatrics 113(2):381. https://doi.org/10.1542/peds.113.2. 381

22. Demers C, Gélinas I, Carret A-S (2016) Activities of daily living in survivors of childhood brain tumor. Am J Occup Ther 70(1): 7001220040p7001220041. https://doi.org/10.5014/ajot.2016. 014993

23. Frange P, Alapetite C, Gaboriaud G, Bours D, Zucker J, Zerah M, Brisse H, Chevignard M, Mosseri V, Bouffet E, Doz F (2009) From childhood to adulthood: long-term outcome of medulloblastoma patients. The Institut Curie experience (1980-2000). J NeuroOncol 95(2):271-279. https://doi.org/10.1007/s11060-009-9927-z

24. Gunn ME, Mört S, Arola M, Taskinen M, Riikonen P, Möttönen M, Lähteenmäki PM (2016) Quality of life and late-effects among childhood brain tumor survivors: a mixed method analysis. Psycho-Oncology 25(6):677-683. https://doi.org/10.1002/pon. 3995

25. Nicklin E, Velikova G, Hulme C, Rodriguez Lopez R, Glaser A, Kwok-Williams M, Boele F (2019) Long-term issues and supportive care needs of adolescent and young adult childhood brain tumour survivors and their caregivers: a systematic review. PsychoOncology 28(3):477-487. https://doi.org/10.1002/pon.4989

26. Tong A, Sainsbury P, Craig J (2007) Consolidated criteria for reporting qualitative research (COREQ): a 32-item checklist for interviews and focus groups. Int J Qual Health Care 19(6):349357. https://doi.org/10.1093/intqhe/mzm042

27. Francis JJ, Johnston M, Robertson C, Glidewell L, Entwistle V, Eccles MP, Grimshaw JM (2010) What is an adequate sample size? Operationalising data saturation for theory-based interview studies. Psychol Health 25(10):1229-1245. https://doi.org/10.1080/ 08870440903194015

28. Braun V, Clarke V (2006) Using thematic analysis in psychology. Qual Res Psychol 3(2):77-101. https://doi.org/10.1191/ 1478088706qp063oa

29. Braun VCV (2013) Successful qualitative research: a practical guide for beginners. SAGE Publications, London

30. Stuckey HL (2014) The first step in data analysis: transcribing and managing qualitative research data. J Soc Health Diabetes 2(1): 006-008. https://doi.org/10.4103/2321-0656.120254

31. Clarke V, Braun V, Hayfield N (2015) Thematic analysis. In: Smith J (ed) Qualitative psychology: a practical guide to research 
methods. In: Qualitative psychology: a practical guide to research methods. SAGE Publications, London, pp 222-248

32. Wasilewski-Masker Karen G-MJ, Kristen V, Kristen C, Amy B, Amanda M, Jennifer P, Lillian M, Mertens AC (2016) Adolescent and young adult perceptions of cancer survivor care and supportive programming. J Commun Support Oncol 14(7):291-298

33. D'Agostino NM, Edelstein K (2013) Psychosocial challenges and resource needs of young adult cancer survivors: implications for program development. J Psychosoc Oncol 31(6):585-600. https:// doi.org/10.1080/07347332.2013.835018

34. Deatrick JA, Mullaney EK, Mooney-Doyle K (2009) Exploring family management of childhood brain tumor survivors. J Pediatr Oncol Nurs 26(5):303-311. https://doi.org/10.1177/ 1043454209343210

35. Vance YH, Eiser C, Horne B (2004) Parents' views of the impact of childhood brain tumours and treatment on young people's social and family functioning. Clin Child Psychol Psychiatry 9(2):271288. https://doi.org/10.1177/1359104504041923

36. Abraham A, Silber T, Lyon M (1999) Psychosocial aspects of chronic illness in adolescence. Indian J Pediatr 66(3):447-453. https://doi.org/10.1007/BF02845539
37. Stensvold E, Stadskleiv K, Myklebust TÅ, Wesenberg F, Helseth E, Bechensteen AG, Brandal P (2020) Unmet rehabilitation needs in $86 \%$ of Norwegian paediatric embryonal brain tumour survivors. Acta Paediatr 109(9): 1875-1886. https://doi.org/10.1111/apa. 15188

38. Van Laar M, Glaser A, Phillips RS, Feltbower RG, Stark DP (2013) The impact of a managed transition of care upon psychosocial characteristics and patient satisfaction in a cohort of adult survivors of childhood cancer. Psycho-Oncology 22(9):2039-2045. https://doi. org/10.1002/pon.3248

39. Barakat LP, Li Y, Hobbie WL, Ogle SK, Hardie T, Volpe EM, Szabo MM, Reilly M, Deatrick JA (2015) Health-related quality of life of adolescent and young adult survivors of childhood brain tumors. Psycho-Oncology 24(7):804-811. https://doi.org/10.1002/ pon.3649

40. Geiger AM, Castellino SM (2011) Delineating the age ranges used to define adolescents and young adults. J Clin Oncol 29(16):e492e493. https://doi.org/10.1200/JCO.2011.35.5602

Publisher's note Springer Nature remains neutral with regard to jurisdictional claims in published maps and institutional affiliations. 